\title{
Educação (de Tempo) Integral e a Constituição de Territórios Educativos
}

\author{
Lúcia Helena Alvarez Leite' \\ Paulo Felipe Lopes de Carvalho'
}

'Universidade Federal de Minas Gerais (UFMG), Belo Horizonte/MG - Brasil

RESUMO - Educação (de Tempo) Integral e a Constituição de Territórios Educativos. $\mathrm{O}$ artigo discute a relação entre escola e território, a partir da abertura da escola em direção ao bairro e à cidade no âmbito do Programa Escola Integrada\PEI, experiência de ampliação de jornada escolar de Belo Horizonte/MG. A partir de uma pesquisa etnográfica que envolveu um grupo de adolescentes e educadores participantes do Programa, foi possível compreender que a constituição de territórios educativos relaciona-se fortemente ao vínculo de educadores e educandos com o bairro. Esses elementos, que conformam a tessitura do território educativo, têm possibilitado a emergência de ações coletivas, via escola, com a melhoria de espaços na comunidade e proporcionado um processo educativo mais próximo da vivência cotidiana dos educandos.

Palavras-chave: Educação Integral. Território. Territórios Educativos.

ABSTRACT - Full-time Education and the Establishment of Educational Territories. This article discusses the relationship between school and territory, from the opening of the school towards the neighborhood and the city, under the scope of the Integrated School Program (PEI), an experience of extension of the school day in Belo Horizonte/MG, Brazil. From an ethnographic study, involving a group of adolescents and educators participating in this program, it was possible to understand that the constitution of educational territories is strongly related to the bond between teachers and students with the neighborhood. These elements, which create the weaving of the educational territory, have allowed the emergence of collective actions, through the school, with the improvement of spaces in the community and have provided an educational process closer to the students' daily life.

Keywords: Full-time Education. Territory. Educational Territories.

Educação \& Realidade, Porto Alegre, v. 41, n. 4, p. 1205-1226, out./dez. 2016.1205 http://dx.doi.org/10.1590/2175-623660598 
Educação (de Tempo) Integral e a Constituição de Territórios Educativos

\section{Introdução}

Este artigo deriva de uma pesquisa de mestrado, concluída em 2014, que teve como objeto de estudo o Programa Escola Integrada (PEI) da Secretaria Municipal de Educação de Belo Horizonte/SMED - BH e os processos de formação de territórios educativos propiciados a partir de sua implementação. A construção da pesquisa partiu do pressuposto de que muitas experiências, políticas, programas e projetos contemporâneos em Educação Integral e em tempo integral, no Brasil, estão se dedicando a articular as dinâmicas e processos formativos vivenciados na escola com aqueles vivenciados nos territórios do bairro e da cidade (Brasil, 2009).

Assumimos aqui uma concepção de Educação Integral que vai além da expansão da jornada escolar, embora compreendendo que esta ampliação pode contribuir para o desenvolvimento da Educação Integral. Pressupõe-se que a questão do tempo estendido esteja aliada à ampliação das possibilidades formativas dos sujeitos. Aponta-se assim, para uma compreensão de Educação Integral que seja capaz de desenvolver uma formação de crianças e jovens que tangencie os campos da cultura, da relação com a comunidade e com a família e do diálogo com o território. A ampliação do tempo dialoga, nessa perspectiva, com a vivência desse tempo estendido.

A aprendizagem acontece ao longo de toda a vida em diferentes contextos: na família, na escola, na cidade; em espaços formais e informais [...]. No entanto, é preciso entender, também, que tempo e espaços escolares devem ser preenchidos com novas oportunidades para a aprendizagem e a reapropriação de espaços de sociabilidade e comunicação com a comunidade local, regional e global (Brasil, 2008, p. 35).

Entendemos assim que a ampliação da jornada escolar, nessa ótica, pode se enriquecer de significados no processo de apropriação de novos espaços e territórios, se conectada à ideia de que o horário integral leve a uma expansão de oportunidades para os sujeitos. Do ponto de vista da Educação Integral para as classes populares que aqui estamos discutindo, Arroyo (2012a) radicaliza ao afirmar que se oferecermos mais escola na mesma lógica do que, historicamente, é oferecido no processo de escolarização, estaremos perdendo o significado político desses programas que objetivam a promoção da Educação Integral para as classes populares ${ }^{1}$.

Se um turno já é tão pesado para tantos milhões de crianças e adolescentes condenados a opressivas reprovações, repetências, evasões, voltas e para tão extensos deveres de casa, mais uma dose do mesmo será insuportável (Arroyo, 2012a, p. 33).

1206 Educação \& Realidade, Porto Alegre, v. 41, n. 4, p. 1205-1226, out./dez. 2016. 
Focalizamos aqui a importância do papel do território na discussão sobre Educação Integral, uma vez que a ampliação da jornada escolar que objetive a ampliação da formação dos educandos deve estar conectada com o território e com a comunidade local. Além disso, ao encontro das concepções aqui apresentadas, o território também assume um caráter popular, assim como entendido na discussão trazida por Santos (2000). O autor coloca que o território se estabelece a partir da utilização a ele atribuída e das relações sociais que o compõem, atribuindo um caráter dinâmico à categoria. tudo ao considerarmos o povo e o território como realidades indissoluvelmente relacionadas. Daí a necessidade de revalorizar o dado local e revalorizar o cotidiano como categoria filosófica e sociológica, mas como uma categoria geográfica e territorial (Santos, 2000, p. 121).

Nesse sentido, ao estabelecermos um diálogo entre o território e as práticas educativas em jornada ampliada que exploram espaços para além dos muros da escola, visualizamos processos que desenham e caracterizam um território educativo, como a circulação dos educandos pelo bairro onde a escola se localiza e pela cidade. Esse processo é possível ser percebido na experiência do Programa Escola Integrada, da Rede Municipal de Educação de Belo Horizonte.

A escolha do PEI como foco de análise se deu pelo fato do Programa ter priorizado, em sua concepção, o diálogo com o território da cidade, uma vez que Belo Horizonte faz parte do movimento das Cidades Educadoras; movimento que teve início em 1990 na cidade de Barcelona e hoje é realidade em várias cidades do mundo. Este movimento se iniciou no I Congresso Internacional de Cidades Educadoras, espaço no qual um grupo de cidades, inclusive Belo Horizonte, representadas por seus governos locais, se reuniram e estabeleceram um pacto com o objetivo de trabalhar em conjunto, desenvolvendo projetos e atividades que buscassem a melhoria da qualidade de vida dos habitantes. Assim, a intenção era a participação ativa dos cidadãos no desenvolvimento da própria cidade, de acordo com a carta das Cidades Educadoras redigida na ocasião.

Esta carta foi reescrita e aprovada no VIII Congresso Internacional de Cidades Educadoras em Gênova no ano de 2004, pela Associação Internacional das Cidades Educadoras que tem sede em Barcelona. Os princípios do movimento das Cidades Educadoras estabelecem que a cidade, vista como um espaço comunitário deve ser considerada como um grande espaço educador, onde as pessoas podem aprender na cidade, com a cidade e com as pessoas. De acordo com a carta:

A cidade educadora tem personalidade própria, integrada no país onde se situa é, por consequência, interdependente do território do qual faz parte. É igualmente uma cidade

Educação \& Realidade, Porto Alegre, v. 41, n. 4, p. 1205-1226, out./dez. 2016.1207 
Educação (de Tempo) Integral e a Constituição de Territórios Educativos

que se relaciona com o seu meio envolvente, outros centros urbanos do seu território e cidades de outros países. O seu objectivo permanente será o de aprender, trocar, partilhar e, por consequência, enriquecer a vida dos seus habitantes (Associação das Cidades Educadoras, p. 1, 2004).

A partir do exposto, essa concepção de Cidade Educadora faz por emergir a necessidade de renovação da cidadania, pretendendo que a cidade deixe de ser um lugar de passagem entre a escola e a casa e possa também ser conquistada por crianças e jovens. Assim, a experiência urbana passa a tomar centralidade nos processos educativos. Villar (2001) sugere que são necessárias transformações profundas nas cidades e elas devem estar ligadas a conquistas de espaços públicos, incremento da segurança viária, utilização inovadora das escolas, equipamentos e serviços, dentre outros elementos.

Assim, na perspectiva das Cidades Educadoras, estabelecemos um diálogo entre as práticas educativas desenvolvidas no PEI e o desenvolvimento de territórios educativos, considerando as seguintes questões: que agentes institucionais, formais, não formais, materiais e simbólicos têm atuação efetiva na tentativa de desenvolvimento e construção de um território educativo, considerando Belo Horizonte como uma Cidade Educadora? Em que medida as ações educativas do PEI se relacionam com seus contextos sociais? Como essas ações dialogam com o território e com as dinâmicas do bairro e da cidade onde a escola está?

\section{Metodologia}

Para o desenvolvimento da pesquisa, utilizou-se a abordagem qualitativa de inspiração etnográfica. A escolha desse campo metodológico decorreu de sua tradição compreensiva ou interpretativa. Segundo considerações de Alves-Mazzotti e Gewandsznajder (1999), a pesquisa qualitativa pressupõe que as pessoas, por natureza, agem em função de crenças, percepções, sentimentos e valores, isso leva a imprimirmos sempre um sentido ao comportamento dos sujeitos.

Considerando Belo Horizonte como o município onde se desenvolveu esta pesquisa, no processo de construção dos dados houve também uma preocupação que reside na relação da cidade com a etnografia. Reportamo-nos assim à literatura de Magnani (2002) que, ao propor uma etnografia urbana, ou seja, no ambiente das cidades, preocupa-se em entender culturalmente as diversas maneiras como as pessoas se sociabilizam nas grandes cidades.

Nessa perspectiva, há, como abordado pelo autor, uma preocupação eminente na literatura sobre o urbano que discute as características e as relações existentes nas cidades, no âmbito da pesquisa etnográfica. Segundo Magnani (2002), os estudiosos que se dedicam à referida discussão privilegiam apenas aspectos econômicos sobre o espaço e o 
território urbano, mas, nesse contexto, é necessário também, em uma etnografia nas grandes cidades, um exercício de se observar os fenômenos e interpretá-los a partir do olhar de perto e olhar de dentro (Magnani, 2002).

Assim, o olhar de perto e de dentro relaciona-se intimamente ao campo da Antropologia. Esse modo de olhar as cidades e seus fenômenos permite perceber dimensões mais subjetivas no ambiente urbano, como, por exemplo, as redes de sociabilidades, a circulação de pessoas na cidade, os modos de deslocamento, os conflitos e disputas, dentre outras características. Dessa maneira, conferimos mais visibilidade aos sujeitos que ocupam as cidades. Nesse sentido, Magnani (2002) coloca questões que sugerem outro olhar sobre as cidades, para além do quadro caótico, geralmente exposto pelos autores que discutem o tema.

Nesse sentido, segundo considerações de Magnani (2002), a etnografia em ambientes urbanos deve vislumbrar seus atores sociais e suas práticas cotidianas, seus lugares de lazer, trabalho, as formas de sociabilidade na cidade, dentre outras possíveis dinâmicas engendradas pelos sujeitos na vida citadina, processos que buscamos apreender no desenvolvimento da pesquisa, olhando de perto os deslocamentos dos adolescentes envolvidos no PEI, nas dinâmicas do bairro em que a escola está inserida e na cidade, como um todo.

De acordo com o exposto, adentramos em um território singular em Belo Horizonte, o Alto Vera Cruz, bem como em uma escola pertencente ao bairro, a Escola Municipal Admirável ${ }^{2}$, onde a dinâmica do PEI foi acompanhada durante o ano letivo de 2013 e parte do ano letivo de 2014. O trabalho compreendeu no acompanhamento contínuo de um grupo de 05 adolescentes participantes do PEI em seus percursos escolares diários, tanto no turno de origem (regular) quanto no turno ampliado.

Durante o processo empírico da pesquisa, foi proposto que os educandos confeccionassem mapas mentais representando suas relações e percepções sobre o bairro e a cidade a partir da experiência no Programa Escola Integrada. Vale ressaltar que mapas mentais são desenhos, no qual o sujeito que o produziu expõe sua relação com determinado espaço, utilizando uma abordagem que considera as representações do vivido, uma expressão das pessoas com os lugares experimentados por elas. Sugere-se que sua confecção seja realizada em forma de teia, onde a ideia principal é colocada no centro de uma folha de papel em branco e utilizada na horizontal para proporcionar maior visibilidade. Podemos interpretá-los como representações construídas por "sujeitos históricos reais, reproduzindo lugares reais vividos, produzidos e construídos materialmente" (Kozel; Nogueira, 1999, p. 240). Buscamos assim, a partir dos mapas mentais, uma expressão do sensível e do vivido no contexto do PEI, assim como sugere Kozel (2009). Desse modo, os educandos expuseram símbolos internalizados que se relacionavam intimamente com suas vivências espaciais no Alto Vera Cruz. 
Educação (de Tempo) Integral e a Constituição de Territórios Educativos

Ao longo do processo empírico ainda realizamos entrevistas coletivas e individuais com os educadores envolvidos no PEI, pois percebemos que esses sujeitos tinham fundamental importância nos processos inerentes à constituição de territórios educativos. Vale frisar que diversas experiências de ampliação da jornada escolar, assim como PEI, têm se caracterizado pela inserção de novos perfis profissionais no âmbito da escola. No contexto investigado, dois perfis profissionais têm se destacado, a professora comunitária, efetiva na Rede Municipal de Educação de Belo Horizonte designada para coordenar as atividades do Programa. Há também, os educadores que coordenam as oficinas, que podem ser agentes culturais da comunidade ou universitários estagiários. As entrevistas realizadas com esses sujeitos complementaram os dados da pesquisa etnográfica feita ao longo da pesquisa.

\section{O Contexto Investigado: o programa escola integrada de Belo Horizonte}

O Programa Escola Integrada (PEI) insere-se no escopo das experiências atuais de Educação Integral que vislumbram a perspectiva de formação dos territórios educativos. Desenvolvido pela Secretaria Municipal de Educação de Belo Horizonte, o PEI está em curso desde 2006, a partir de 07 escolas piloto. O Programa almeja desenvolver uma Educação Integral e Integrada a partir da extensão da jornada escolar em cinco horas diárias, além das quatro horas tradicionalmente verificadas na disposição do tempo escolar, totalizando uma jornada de nove horas por dia.

O Programa é organizado na dinâmica de oficinas, que são desenvolvidas no horário oposto ao dedicado às disciplinas regulares. A lógica de organização pressupõe que as oficinas sejam voltadas para quatro grandes áreas: Conhecimentos Específicos; Acompanhamento Pedagógico/dever de casa; Formação pessoal e social; Cultura, Artes, Lazer e Esporte.

As atividades escolares no âmbito do PEI são desenvolvidas a partir de parcerias, com o apoio de diversos espaços sociais e instituições como ONG's, associações comunitárias, centros de cultura, parques, clubes, igrejas, universidades, dentre outras. Essas instituições contribuem de maneiras diversas para o desenvolvimento do Programa, principalmente cedendo espaços para a realização das oficinas. Assim sendo, o Programa Escola Integrada pode ser caracterizado como um programa articulador entre escolas, comunidade, universidades e as diversas Secretarias do Município. O PEI abarca, como dito anteriormente, a concepção de Cidade Educadora, assumindo a cidade como território educativo, complexificando a relação escola-comunidade, na medida propõe um projeto educativo territorial, agregando outros agentes e instituições educativas além da escola.

1210 Educação \& Realidade, Porto Alegre, v. 41, n. 4, p. 1205-1226, out./dez. 2016. 


\section{Programa Escola Integrada no Alto Vera Cruz}

A pesquisa foi empreendida em uma escola municipal do bairro Alto Vera Cruz, localizada na periferia de Belo Horizonte. Esse bairro é marcado por consonâncias e dissonâncias sociais e culturais; se por um lado, a falta de infraestrutura do bairro marca uma diferença social em relação a outros bairros, acentuando sua situação de pobreza, principalmente devido à intensidade da violência urbana; por outro, as ações coletivas, desenvolvidas pelas diversas mobilizações de caráter popular ao longo de toda a história do Alto Vera Cruz, faz por emergir o sentido de comunidade e solidariedade entre os moradores. Isso leva à expressão de manifestações culturais várias, bem como a chegada de instituições e organizações no território que têm atuação preponderante no desenvolvimento social do bairro.

No que concerne à infraestrutura da escola, não há problemas quanto à espacialidade e materialidade, havendo espaços reservados também no interior da escola para as atividades relativas ao PEI. A escola é muito bem equipada e atende a demanda de educandos matriculados. A instituição tem uma área total construída de aproximadamente 10.000 metros quadrados. Os equipamentos e espaços presentes na escola são: laboratório de informática, laboratório de ciências, biblioteca, laboratório de culinária, duas salas específicas para oficinas do PEI, refeitório, quadra poliesportiva, bloco administrativo, além de ter um pátio externo grande o suficiente para o número de educandos.

Na época da pesquisa de campo (2013; 2014) a escola tinha 1327 alunos matriculados nas diversas etapas e modalidades da educação básica: educação infantil (a partir de três anos); primeiro, segundo e terceiro ciclo do Ensino Fundamental e EJA (Educação de Jovens e Adultos).

O Programa Escola Integrada foi implantado na Escola Municipal Admirável em 2008. Em conversa com a professora comunitária da escola, foi relatado que o processo de implantação do programa na escola foi tranquilo. Na ocasião, ela estava deixando um mandato como diretora da escola. Vale destacar que essa profissional sempre se preocupou em estabelecer articulações com a comunidade. Devido a isso, foi convidada pela gestão que a sucedeu, a ocupar o cargo de professora comunitária.

Atualmente o PEI funciona nos dois turnos, manhã e tarde, sendo que no primeiro turno atende as crianças que à tarde frequentam o Primeiro ciclo e o Primeiro ano do Segundo Ciclo do Ensino Fundamental. Já na parte da tarde, frequentam o PEI aqueles educandos que pela manhã estão matriculados nos anos finais do Segundo Ciclo e no Terceiro Ciclo. Desse modo, o PEI tem aproximadamente 400 alunos no primeiro turno, divididos em 8 turmas diferenciadas por cores e aproximadamente 360 alunos no turno da tarde, divididos em 9 turmas. A média de

Educação \& Realidade, Porto Alegre, v. 41, n. 4, p. 1205-1226, out./dez. 2016.1211 
Educação (de Tempo) Integral e a Constituição de Territórios Educativos

alunos por turma é 25. Ressalta-se que as turmas não são as mesmas do turno regular, mas sim mescladas.

No PEI, os estudantes seguem uma rotina. Os que frequentam o PEI pela manhã chegam à escola às 08 h30 e tomam o café da manhã. Saem para as oficinas, retornando às 11h30; almoçam, têm um intervalo de descanso e às $13 \mathrm{~h}$ se dirigem para as salas onde terão as aulas regulares. Aqueles que estudam pela manhã chegam à escola às $7 \mathrm{~h}$ para as aulas regulares, às $11 \mathrm{~h} 30$ almoçam e ficam na quadra até às $12 \mathrm{~h} 45$, horário em que saem para as oficinas. Às $16 \mathrm{~h}$ os educandos retornam para a escola, fazem o último lanche do dia e às $16 \mathrm{~h} 30$ são liberados pela escola.

Quanto às oficinas, a escola oferece as atividades de artesanato, skate, produção de jornal, culinária, dança, teatro e circo, informática, acompanhamento pedagógico, pré-cefet, esportes, polo aquático, pintura nos muros e horta. E os espaços utilizados para o desenvolvimento das oficinas são: CEVAE (Centro de Vivência Agroecológica), praça Padre Marcelo, Associação Comunitária Alto Vera Cruz, clube Santa Cruz e esporadicamente o Centro Cultural Alto Vera Cruz.

No âmbito das oficinas, vale ressaltar que a escola desenvolve duas ações de comunicação ligadas à divulgação das atividades do PEI e do bairro. São confeccionados dois jornais de circulação local. O Boletim do Escola Integrada, divulgado mensalmente para a escola e comunidade. Produzido pela professora comunitária, nele há relatos do desenvolvimento das atividades no PEI, dicas de espaços para se visitar no bairro e na cidade, convites para atrações culturais. Na escola, ainda é confeccionado o Jornal Alto Notícias produzido pelos educandos na oficina de produção de jornal e tem circulação bimestral. O objetivo do referido jornal é divulgar notícias diversas sobre o bairro e para isso os educandos são incentivados ao exercício da pesquisa no âmbito do território do Alto Vera Cruz.

O deslocamento para os espaços no exterior da escola, na maioria das vezes, é realizado a pé, com exceção do clube Santa Cruz, que é mais longe e em determinados períodos do ano, de acordo com a verba, a escola conta com um ônibus para o deslocamento. Na falta de verba, os educandos caminham até o clube para a realização das oficinas. Os outros espaços utilizados estão bem próximos à escola e existem poucos problemas no que tange ao deslocamento.

Ainda em relação à circulação, a dimensão da cidade na experiência da escola investigada corrobora a concepção de cidade educadora assumida pelo PEI, uma vez que no âmbito da escola são organizadas e realizadas diversas excursões pedagógicas e aulas passeios durante o ano letivo. Essa característica oportuniza aos estudantes conhecerem outros espaços educativos na cidade, no estado de Minas Gerais, como o Museu do Inhotim, a serra do Caraça e até mesmo outros estados, como a cidade do Rio de Janeiro, o Museu Imperial e a casa de Santos Dumont em Petrópolis, dentre outros.

1212 Educação \& Realidade, Porto Alegre, v. 41, n. 4, p. 1205-1226, out./dez. 2016. 
Desde o início de sua existência, a escola tem se dedicado a aproximar e estreitar os laços com a comunidade do bairro, seja pela inserção de membros da comunidade nos processos educativos, seja na implementação de diversos programas e projetos que se dedicam a estimular a relação escola-comunidade.

Assim, devido a essa característica histórica de aproximação com o bairro, a escola tem conseguido desenvolver o PEI de acordo com suas concepções, que como já abordado, privilegia dentre seus objetivos a relação significativa entre escola, bairro, cidade e seus sujeitos.

\section{O Território Educativo: entre raízes, pedaços e a efetivação do lugar}

Os dados qualitativos construídos no percurso metodológico da pesquisa nos permitiram compreender que os processos de constituição dos territórios educativos são intensos e complexos. Dentre eles, um dos resultados a se observar a partir da dinâmica do PEI, reside na visualização de um espaço geográfico educativo composto de fixos e fluxos que se interagem (Santos, 2009).

Esse espaço, particular pela presença do PEI no bairro, tem influência central no desenvolvimento do território educativo, pois é o palco onde as relações humanas presentes na dinâmica do Programa acontecem, articuladas às vivências espaciais dos moradores do Alto Vera Cruz. Nesse contexto, a configuração do território educativo tem relação com o sistema de fixos e fluxos que compõe o espaço geográfico, palco dos processos de territorialização que constituirão o território educativo. Para Santos (2009), os fixos são elementos que se relacionam à estrutura física do espaço, como estradas, pontes, construções, barragens. Já os fluxos são os movimentos condicionados pelas ações desenvolvidas no espaço, havendo assim uma forte interação entre esses elementos. Tal interação é capaz de construir e reconstruir o espaço.

No âmbito de nossa investigação, ao atentar o olhar especificamente para a o Alto Vera Cruz, os principais elementos fixos do espaço geográfico educativo são: a própria escola, o clube Santa Cruz, o CEVAE e a associação comunitária do bairro, espaços onde são desenvolvidas as oficinas.

No bairro, ainda existem outras instituições parceiras do PEI, que esporadicamente desenvolvem atividades em articulação com o Programa e recebem também a escola em seus espaços em determinadas ocasiões e eventos escolares que acontecem no bairro. Como exemplo, podemos citar os espaços do Centro Cultural Alto Vera Cruz e a organização CIAME, aqui também considerados como elementos fixos. Considerando o espaço da cidade, os fixos são representados principalmente pelos espaços que recebem os estudantes para atividades relacionadas às aulas-passeios e excursões pedagógicas. Essas são propiciadas pelo

Educação \& Realidade, Porto Alegre, v. 41, n. 4, p. 1205-1226, out./dez. 2016.1213 
Educação (de Tempo) Integral e a Constituição de Territórios Educativos

PEI para atividades didáticas e de lazer, além de serem corriqueiras as idas a cinemas, teatros, festivais culturais, museus, parques, dentre outros.

Os fluxos, no contexto aqui esboçado, são representados pelos movimentos condicionados pelas ações (individuais ou coletivas) desenvolvidas pelos sujeitos entre os elementos fixos. Em nosso caso, os fluxos são representados pela circulação das crianças e jovens pelo bairro e a cidade, pelas negociações necessárias para usufruto e apropriação desses espaços, pela circulação de ideias geradas pelos educandos em circulação no bairro, pelo compartilhamento de suas histórias de vida. Além disso, esses elementos produzem saberes no âmbito da constante relação estabelecida com os elementos fixos.

Ao visualizar este espaço e perceber as relações que ali se dão nos âmbitos da escola, do bairro e da cidade, percebemos também processos de territorialização vários. Dentre eles, destacamos aqui o vínculo que os sujeitos do Alto Vera Cruz estabelecem com o território, bem como as relações dos educadores do território ao humanizar a e interrogar a docência.

A partir da dinâmica desenvolvida por essas relações, percebe-se um território educativo composto de multiterritorialidades e que afirma a identidade da comunidade e do território do entorno escolar, na medida em que são imbricadas as relações educacionais produzidas pela escola e a presença de educandos nos espaços do bairro; elementos esses que valorizam e intensificam, mesmo frente às relações de poder, a identidade territorial e o sentido de bairro (vizinhança). Assim, o território educativo ao se conceber fluido e múltiplo, incorpora um caráter multiterritorial. Nesse sentido:

\begin{abstract}
[...] o território, como espaço dominado e/ou apropriado, manifesta hoje um sentido multi-escalar e multidimensional que só pode ser devidamente apreendido dentro de uma concepção de multiplicidade, de uma multiterritorialidade. Toda ação que se pretenda efetivamente transformadora, hoje, necessita, obrigatoriamente, encarar esta questão: ou se trabalha com a multiplicidade de nossos territórios, ou não se alcançará a transformação que almejamos (Haesbaert, 2007, p. 42-43).
\end{abstract}

Nesse sentido, o que chamou atenção durante todo o trabalho de campo foi perceber como o sentimento de pertença ao Alto Vera Cruz foi e é determinante no delineamento do território educativo. Inúmeras vezes foram percebidos, no campo, eventos de sociabilidade que se assemelhavam, por exemplo, às relações familiares. Relações essas percebidas principalmente pela proximidade entre os sujeitos ao se comunicarem de distintos e diversos modos, ou seja, nas conversas entre os educandos, na relação dos educandos com os oficineiros, entre os diálogos dos oficineiros, nos encontros dos educandos com os moradores da comunidade quando no bairro eles caminhavam. Além disso, 
relatos de diversos sujeitos durante a investigação afirmavam o quanto eles atribuíam um sentimento de vínculo com aquele território. É importante dizer que o vínculo que estamos abordando não se estabelece somente pelo fato do sujeito ter nascido ou viver no referido território, mas, principalmente, por reconhecê-lo enquanto espaço de reprodução da vida e a partir disso focalizar mudanças e novos modos de apropriação.

Nesse sentido, nos atentemos para os seguintes diálogos:

Pesquisador: Você acha que seu sentimento pelo bairro, tem a ver com a presença dessa escola aqui no Bairro?

Henrique: Os dois tão juntos né. Porque, os meus pais já estudaram aqui já, onde eu nasci os meus pais já estudaram aqui já. É importante essa escola aqui, porque tanta escola que tem aqui em volta. Eu gostei dessa escola para estudar. É perto de casa também. E eu gosto daqui dessa escola. Ainda mais que esse é o meu último ano. Eu nem sei como eu vou segurar quando eu sair dessa escola.

Xisto: É diferente né?! Por causa que lá (os diversos espaços das aulas passeios) é uma coisa e aqui (O Alto Vera Cruz) é outra.

Pesquisador: Mas o que você acha diferente?

Xisto: As pessoas, o jeito delas. Aqui elas é de um jeito e lá é de outro.

Pesquisador: Como assim?

Xisto: Lá elas são mais bobas né. Tipo assim..

Professora Comunitária: Aqui é um bairro muito unido, então quando tem algum problema a gente junta pra resolver as questões. Por exemplo, a questão do lixo perto do posto de saúde, a comunidade inteira se envolveu, a semana inteira fazendo atividade, foi aquela coisa.

Com base nos dados apresentados, podemos perceber como a questão dos vínculos territoriais é intensa na experiência do PEI na Escola Municipal Admirável. Ao vislumbrarmos a fala de Henrique, é nítida a percepção da relação estreita entre o bairro e a escola. Ao ser indagado sobre o porquê do sentimento de intimidade e amor pelo bairro, o educando o relaciona imediatamente com a presença da escola naquele território. Ao dizer que seus pais ali estudaram, o educando evidencia um sentimento de pertencimento com o território ao relacionar suas raízes familiares à experiência escolar que ele vivencia.

Em referência à fala de Xisto, ao comparar as relações percebidas em outros espaços, os quais ele entrou em contato via aulas-passeios ou excursões pedagógicas, percebe-se que imediatamente há uma comparação com as vivências no bairro e com as percepções que carrega sobre o Alto Vera Cruz. Ao discorrer sobre as pessoas que vivem nesses diferentes territórios, o educando diferencia claramente seus modos de ser. Nessa comparação, as pessoas de lá, ou seja, que não pertencem ao território do Alto Vera Cruz são consideradas pelo educando como mais bobas, o que marca uma diferença cultural entre as experiências extraterritoriais e aquelas tecidas no território do bairro, as quais geram o sentimento de intimidade. 
Educação (de Tempo) Integral e a Constituição de Territórios Educativos

Já a fala da professora comunitária expõe como o Alto Vera Cruz é marcado pelo envolvimento da comunidade em ações coletivas que visam à melhoria do bairro. Aqui, vale ressaltar a ação da escola, que se coloca como instituição indutora de algumas ações, o que se dá pelo fato da escola ser referência institucional na comunidade ao reconhecer as características territoriais do bairro. Aliado a isso, o vínculo que a professora comunitária estabelece com o Alto Vera Cruz potencializa essas ações, uma vez que busca, a partir do vínculo territorial, modificações do espaço, modificações essas que podem levar os sujeitos a criarem novas relações com determinado espaço. A esse respeito, quando a escola se conecta ao bairro, ações coletivas podem ser desenvolvidas com vistas a modificar o espaço e torná-lo mais propício para atividades educativas, e também para a reprodução da vida no cotidiano do território onde a escola se localiza. Emerge assim, uma relação dialógica entre a escola e o seu entorno.

O relato da professora comunitária evidencia também que, coletivamente, através de uma atividade do PEI, a comunidade se envolve com um problema, o acúmulo de lixo no bairro, a fim de minimizá-lo ou resolvê-lo. É interessante constatar também que a escola, enquanto veículo de difusão da informação, pode sensibilizar a comunidade do entorno para enxergar esse tipo de problema com um olhar mais sensível, o que pode motivá-los a participarem de ações de melhoria do território e potencializar aquelas já existentes, que muito ensinaram à escola. A questão do lixo, aqui tratada, foi também denunciada pela escola através de um jornal de circulação local produzido pelos próprios alunos integrantes do PEI em uma oficina específica de editoração e produção deste jornal.

A escola então contribui para potencializar os vínculos de pertencimento dos educandos e dos moradores com o espaço do bairro e com o espaço da escola, que podem superar os sentimentos de aversão tão costumeiramente veiculados e vinculados a escolas públicas e bairros de periferia, contextos aqui analisados. Portanto, os vínculos territoriais podem possibilitar o sentimento de pertencimento por parte dos sujeitos a partir de ações que reabilitam e causam melhorias no espaço; ações que são desenvolvidas no âmbito das dinâmicas do PEI ao se encontrar com a dinâmica do território do bairro. Assim, ambos potencializam-se.

Nesse sentido, segundo considerações de José de Deus (2010), os sentimentos topofílicos, ou seja, de pertença ao território, associam-se aos lugares valorizados pelos sujeitos. No contexto da pesquisa, visualizam-se as ações de melhorias dos espaços do bairro desenvolvidas pela escola no contexto do Programa Escola Integrada. Ações que objetivam modificar espaços depredados do bairro, a fim de que estes possam ser mais propícios para apropriação tanto dos educandos quanto da comunidade. Essas melhorias físicas e simbólicas no espaço podem ser entendidas como ações de toporeabilitação, que são ações de resgate,

1216 Educação \& Realidade, Porto Alegre, v. 41, n. 4, p. 1205-1226, out./dez. 2016. 
reabilitação ou restauração de lugares paisagens e conjuntos (Amorim Filho, 1999).

Observemos os mapas mentais a seguir produzidos pelos educandos inseridos no PEI:

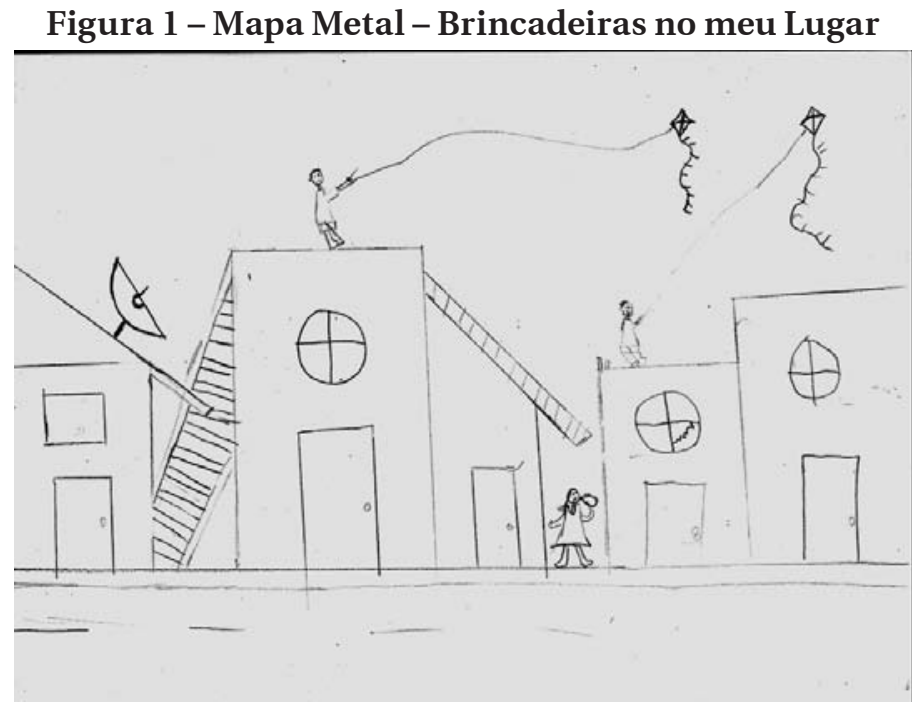

Fonte: Educando\PEI.

Figura 2 - Coleta de Lixo e ONG's no Alto Vera Cruz

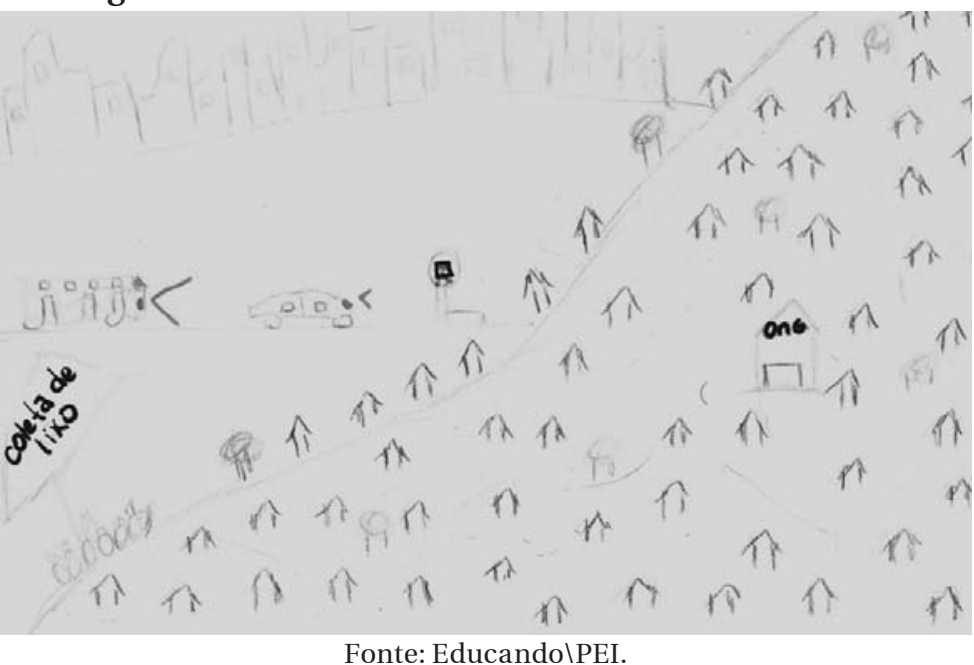

Na primeira imagem, podemos perceber a experiência do território calcada nas brincadeiras que ali costumeiramente acontecem. Já na segunda imagem, o território é vislumbrado a partir de representação de ações que, a princípio, vão atuar na valorização do espaço vivido, como a coleta de lixo e a presença de ONG's.

Educação \& Realidade, Porto Alegre, v. 41, n. 4, p. 1205-1226, out./dez. 2016.1217 
Educação (de Tempo) Integral e a Constituição de Territórios Educativos

A partir dos mapas mentais apresentados, corroboramos a ideia de que um dos processos de formação de territórios educativos tem vinculação com o sentimento de pertença dos sujeitos com o espaço do bairro, o que encontra relação com a concepção de Carlos (1996, p. 201), para quem o lugar se configura como "uma porção do espaço apropriável para a vida - apropriada através do corpo - dos sentidos - dos passos de seus moradores". Com isso, os seres “[...] humanos atribuem significados e organizam o espaço de acordo com os símbolos que constroem a partir de sua percepção" (Kozel, 2010, p. 5).

Assim, podemos perceber como a imagem do bairro para alguns adolescentes guarda uma relação de vínculo, intimidade e efetivação do espaço enquanto palco de experiências e relações sociais. Nesse sentido, afirma-se uma identidade no âmbito do território, fazendo-se por desenvolver territorialidades calcadas no espírito de coletividade presentes nas relações do bairro. Processo esse, potencializado com a presença do PEI no bairro, o que consequentemente estreitou os laços da relação escola-território. Quanto a isso:

$\mathrm{O}$ fato de um indivíduo estar num determinado lugar e em um determinado tempo, faz com este mesmo indivíduo participe de redes de sociabilidade que lhe permitem construir seus referenciais com o qual ordena o mundo[...]. A identidade, portanto, não é algo dado, mas é sempre processo (identificação em curso), que se dá por meio da comunicação com outros atores (diálogo e confronto). A territorialidade é expressão desse processo no cotidiano dos atores sociais (Souza; Pedon, 2007, p. 135).

Nessa perspectiva, observemos um diálogo presenciado pelo pesquisador enquanto acompanhava a oficina de culinária, que expressa bem a dimensão do lugar presente na dinâmica do PEI no Alto Vera Cruz. Importa dizer que o adolescente que profere o relato é egresso do Ensino Fundamental na escola e no entanto, continuou a frequentar o PEI pelo vínculo que obteve com o programa.

João: Tati (oficineira de culinária), eu tava de olho vermelho e minha mãe. Ô menino, onde cê tá fumando essa maconha? Deixa eu cheirar sua boca. E eu. Que isso ó?! Quando minha mãe me bate eu corro pra casa do meu avô, mas não consigo correr pra rua.

Elizabeth: Vixi ó, uma vez minha mãe me deu um tapa aqui (apontou para cara) só porque eu tava com olho pequeno e vermelho. Ela achou que eu tinha fumado maconha.

Oficineira: Mas isso é medo gente, medo de vocês fazerem coisa errada. João: Mas quando minha mãe me bate eu não consigo correr pra rua eu só consigo cortar o caminho da casa do meu avô. Tipo assim ó. Aqui tá a rampa (acenando com os dedos na mesa) se descer aqui tá na rua e a casa do meu avô tá no meio da rampa. Eu consigo ir pra rua, vou direto pra casa do meu avô.

João: E quando minha mãe chega bêbada e inventa de me pegar pelo gogó. Esses dias eu quase matei minha mãe, ela chegou bebona né. Aí ela

1218 Educação \& Realidade, Porto Alegre, v. 41, n. 4, p. 1205-1226, out./dez. 2016. 
Leite; Carvalho

oh menino cê tá mexendo com maconha. Pra quê, aí eu: Vamo vê então se eu vou mexer quando crescer. Ela me pegou pelo gogó, pra quê, eu tava encima da minha cama. Já peguei ela assim ó ela me puxou, se eu não puxo ela pra trás ela pra ela tá morta, ela ia bater de cabeça na quininha da minha cama. Minha mãe chega bêbada ela não quer saber de nada não, ela quer é brigar comigo e com a belinha (irmã). Até meu vô que é pai dela, ela fica brigando.

Oficineira: Ela é uma boa mãe, o problema dela é a bebida.

João: Eu sô a fim de crescer.

Oficineira: O problema dela é a bebida.

João: Esses dias eu briguei com ela, dormi fora de casa quatro dias ela ficou doidinha, se não fosse meu irmão ela não tinha me achado. Cheguei em casa né aí ela: Oh meu filho, onde você tava?

Oficineira: Preocupação.

João: Então porque na hora de bater não pensa nisso. Meu irmão já falou bater não adianta nada não.

Oficineira: Sua mãe criou seu irmão, num criou?

João: Criou.

Oficineira: O que seu irmão faz hoje? Ele é drogado?

João: Não

Oficineira: Viciado?

João: Não

Oficineira: Vende maconha?

João: Não

Oficineira: O que ele faz?

João: Trabalha

Oficineira: O que ele faz? Mais enfática.

João: Trabalha

Oficineira: Pois é, você acha que se ela fosse uma má mãe ele estaria como?

João: Eu já virei pra ela e falei, você vai continuar batendo? Quando eu crescer eu quero ver em quem você vai bater. Eu saio de casa na cara dura. Minha mãe dá sorte que eu não trabalho, pois esses dias já era pra ela tá sem eu 'fi'.

Após esse relato do educando, a oficineira relembrou o episódio do dia em que a mãe desse aluno foi contemplada com um apartamento em outro bairro, conquistado por um programa de habitação. Nesse dia, esse adolescente chegou à escola, contou a notícia para alguns colegas mais próximos e eles começaram a chorar escutando Esse Cara Sou $E u$ do cantor Roberto Carlos.

O primeiro resultado a se observar é que o Programa Escola Integrada tem misturado as tramas vividas pelos adolescentes no território do bairro ao processo de escolarização desses sujeitos. A escola então passa a ter um novo sentido, mais intimamente ligado às experiências territoriais. Na fala do educando, por exemplo, ao afirmar várias vezes que não consegue ir para a rua, neste caso, o espaço do uso e venda de drogas, sugere-se que a circulação dos educandos na comunidade tem relação intrínseca à circulação estabelecida em momentos escolarizados.

Educação \& Realidade, Porto Alegre, v. 41, n. 4, p. 1205-1226, out./dez. 2016.1219 
Educação (de Tempo) Integral e a Constituição de Territórios Educativos

Nessa lógica, podemos inferir também que a experiência tem proporcionado a construção de 'pedaços' pelos jovens participantes. No que tange à compreensão da categoria pedaço, ela se relaciona ao dado, uma vez que segundo Magnani (1998), o pedaço se constitui no espaço que se dá entre o público, aqui representado pela escola e o privado, que, nesse caso, é a casa. O que toma centralidade, em nossa análise, é que a experiência de escolarização suscitada pelo PEI engendra 'pedaços', uma vez que os educandos compartilham dos mesmos códigos de linguagem, frequentam os mesmos espaços e compartilham seus enredos de vida, produzindo naquele espaço o reduto de uma sociabilidade que se expressa entre as características do território, as experiências familiares e as experiências escolares. Nesse sentido, o pedaço:

\begin{abstract}
[...] designa aquele espaço intermediário entre o privado (a casa) e o público, onde se desenvolve uma sociabilidade básica, mais ampla que a fundada nos laços familiares, porém mais densa, significativa e estável que as relações formais e individualizadas impostas pela sociedade (Magnani, 1998, p. 116).
\end{abstract}

O pedaço, portanto, estabelece-se quando o espaço, ou parte dele, representa o ponto de referência e distingue determinado grupo de frequentadores (Magnani, 2002). Podemos inferir, assim, que o território educativo é composto também de pedaços, pois é constituído de espaços que agregam relações de intimidade entre grupos que o frequentam, criando relações sociais particulares, via a experiência educativa, que juntamente a outros processos vividos no bairro delineiam o território educativo. Portanto, ao se estabelecer entre o espaço público e o privado, ou seja, entre a rua e a casa, ou entre a escola e a casa, o pedaço se transforma no lugar dos amigos, dos parceiros, supondo, "uma referência espacial, a presença regular dos membros e um código de reconhecimento e comunicação entre eles” (Magnani, 2002, p. 10).

\title{
O Vínculo nas Relações e nas Ações dos Educadores do Território
}

Como afirmamos, a constituição de territórios educativos está intimamente ligada às relações topofílicas que os sujeitos têm com seu espaço de vida, seja no bairro, seja na cidade, seja na escola. Em nossa investigação, essas relações foram percebidas mais fortemente no âmbito do bairro. Ao encontro delas, percebemos também que o fato dos oficineiros serem do território, e nele se identificarem, mostrou-se como elemento importante verificado principalmente a partir da relação dos oficineiros com os educandos.

É importante dizer que esses profissionais, nas experiências em Educação Integral, possuem distintas denominações. Assim,

Na maioria das vezes, tais educadores são jovens e moradores das comunidades nas quais realizam suas ações 
educativas, atuando sobre as mais diferentes denominações como: oficineiros, educadores socioculturais, educadores sociais, arte-educadores, entre outros (Dayrell; Carvalho; Geber, 2012, p. 57).

Nosso contexto de análise corrobora a colocação desses autores, uma vez que a grande maioria dos oficineiros do PEI, na experiência da Escola Municipal Admirável, vivem no Alto Vera Cruz. À época da pesquisa, do total de 13 oficineiros presentes na escola, apenas uma oficineira não era moradora da comunidade, mas sim universitária estagiária. $\mathrm{O}$ fato de pertencerem ao mesmo território dos educandos surge como importante elemento ao delinearmos o território educativo. Atentemos para os seguintes dados levantados em campo:

Oficineiro: é uma confiança que eles têm na gente, principalmente no meu caso. No final de semana eu fico no clube, o clube que eles vão todos os dias, eu fico lá final de semana. Então assim, é muito menino da Escola Integrada que vai lá final de semana. Então lá eles não me veem como monitor. Eles chegam o palavreado já é outro, eles sentam eles querem conversar. É totalmente diferente daqui da escola. Eu acho que eles têm um pouquinho de respeito. Assim como acontece com o povo que mora aqui na comunidade. Quando encontra o professor na rua, é diferente. Eles reparam em tudo, por exemplo, se você está com uma blusinha. Eles falam. O que é isso professora? Nunca te vi usando isso não. Mas porque, aí a gente explica. - Lá é uma coisa aqui é outra, então eu acho que essa convivência que a gente tem com eles, principalmente lá, é muito bom. Porque, porque se o menino tá com problema, não só na minha oficina. Oficineiro: Tipo o apoio que eles encontram.. não encontram na família, eles encontram em nós. A gente passa na rua, nossa (com efusão) a gente vê o Escola Integrada Inteira. Não só da Escola Integrada, até menino que a gente que é da escola e não é da Escola Integrada me conhece. Aí fala: Ei professor! É um apoio mesmo, uma amizade que a gente tem com os meninos, aí rola confiança em nós. Entendeu?

Oficineiro: Eu acho que a confiança é maior quando é do mesmo bairro, porque outros monitores, não têm esse negócio de sair fim de semana e encontrar com aquele menino.

As falas apresentadas evidenciam como os próprios oficineiros reconhecem a importância de viver no mesmo território que os educandos, o que pode auxiliar nos processos educativos. Isso, sobretudo pelo fato de apresentarem vivências culturais, anseios, modos de ser e linguagens semelhantes devido à experiência no mesmo território. Outro elemento que chama a atenção é que os educandos compartilham experiências com eles em momentos não escolarizados, o que pode estreitar a relação entre eles na escola. Quanto a isso:

Além de um conhecimento de território, das dinâmicas que conformam as relações do bairrolcomunidade; esses jovens, por meio de suas expressões culturais e simbólicas, instituem, muitas vezes, um tipo de relação, transmissão cultural e sociabilidade que dificilmente profes- 
Educação (de Tempo) Integral e a Constituição de Territórios Educativos

sores de outros universos socioculturais construiriam (Dayrell; Carvalho; Geber, 2012, p. 159).

A este respeito, Arroyo (2012a) afirma que os Programas de Educação Integral, ao interrogar a docência com a inserção de novos educadores no ambiente escolar, têm aberto um caminho de superação para a afirmação de direitos que historicamente foram negados às infâncias e adolescências populares. Superação essa que se relaciona também ao fato de reconhecermos as crianças e adolescentes como sujeitos de vida, corpo, espaço e tempo, algo que se faz presente na relação dos educadores do território com os jovens participantes do PEI. Assim:

Esses programas nos levam a reconhecer que o ser humano, de criança a adulto, é uma totalidade, com a qual a pedagogia e a docência lidam; que diminuir ao menos a sua fome, sua desproteção, seu precário viver é humanizar, formar, educar, aprender, é trabalho profissional; que as políticas educativas somente serão educativas se atreladas a políticas de garantia de um justo e digno viver (Arroyo, 2012a, p. 44).

A presença desses novos educadores na escola tem afirmado a necessidade de repensarmos a docência, dentro das novas lógicas pedagógicas que a educação integral tem sido responsável por atribuir às escolas. Nesse sentido, a docência dos educadores do território, ou seja, a ação dos oficineiros que ali nasceram, viveram e, por hora, exercem a docência, marca o reconhecimento social dos educandos enquanto sujeitos de direitos.

Além disso, há um reconhecimento também, por parte desses educadores e dos educandos, de que muitos espaços são propícios à aprendizagem, o que confere sentido ao ofício desses educadores. Além disso, foi fácil perceber que os oficineiros do território enxergam os educandos para além da função de alunos, como sujeitos com direitos, vida, percursos, corpos, tramas [...]. A esse respeito,

As novas gerações que frequentam as escolas reconhecem que fora da escola há muitas vivências a experimentar e muitos saberes a aprender. Se tivéssemos uma infância, adolescência e juventude apáticas e passivas diante do desconhecido e ainda não vivido teriam perdido o sentido de aprender e consequentemente estaríamos perdendo o sentido de nosso ofício de mestres (Arroyo, 2000, p. 55).

Percebe-se assim que os educadores do território, em suas práticas, estão humanizando e interrogando a docência na escola. Ao agregar códigos culturais e expressões de linguagem comuns, estes educadores têm se aproximado das crianças e adolescentes, relacionando o ato educativo às reais formas de expressão dos educandos. Eles afirmam assim, sobretudo, uma função social efetiva em suas práticas que se relacionam com as vivências comuns no território onde se inserem. 
A docência, então, é imersa em uma complexa trama de relações que se processam em seu entorno. Relações essas que são elementos essenciais para que o ofício de mestre determine seu lugar social e para quem “[...] este aprendizado só acontece em uma matriz social, cultural, no convívio com determinações simbólicas, rituais, celebrações, gestos” (Arroyo, 2000, p. 54).

Esses educadores do território, juntamente à presença de crianças, adolescentes, jovens e adultos, agregam formas de ver o mundo e consequentemente outras leituras, inclusive das experiências sociais em diversos territórios.

Nesse sentido:

A chegada dos educandos com vidas tão precarizadas às escolas obriga a docência a repor essas bases do viver com a devida centralidade nos processos de aprender, de formação e desenvolvimento humano. $\mathrm{O}$ direito à educação, ao conhecimento, à cultura, está atrelado às formas de viver nas tramas do presente (Arroyo, 2012b, p. 80).

Portanto, compreendemos que a configuração dos processos educativos desencadeados pela presença desses novos educadores na escola, ao se conectar intimamente com as vivências territoriais dos educandos, tem função importante e essencial na construção de territórios educativos.

\section{Palavras Finais}

O Programa Escola Integrada, como programa de ampliação da jornada escolar diária dos estudantes, optou por utilizar este tempo, com ações que dão centralidade ao território e são ligadas ao movimento das cidades educadoras. Assim, o PEI procura produzir um espaço geográfico educativo particular, que ao ser apropriado por diversos sujeitos tecem as relações e os processos que constituirão o território educativo.

No caso da experiência investigada, verificamos que o Programa tem potencializado essas relações e contribuído para valorizar a identidade territorial do bairro, uma vez que tem suscitado a efetivação de sentimentos de pertença ao território.

Aliado ao vínculo com o território, o que leva à expressão das identidades do/no Alto Vera Cruz, a presença dos agentes culturais/oficineiros do território como educadores do tempo ampliado tem relevante papel no processo de constituição dos territórios educativos. Ao compartilharem linguagens, modos de ser e vivências territoriais muitas vezes comuns à dos educandos, eles têm humanizado a docência, oportunizando às crianças e aos jovens uma experiência escolar mais próxima de suas realidades, de seus desejos. Assim, esses educadores representam a inserção de Outros Sujeitos na escola e engendram $\mathrm{Ou}$ tras Pedagogias (Arroyo, 2012b). 
Educação (de Tempo) Integral e a Constituição de Territórios Educativos

Por fim, a discussão que aqui objetivamos fazer, a que centraliza a relação escola-território e os processos daí originados constituindo o território educativo. Ressaltamos o que de mais efetivo consideramos como uma possível contribuição dessa pesquisa. A de que um programa de ampliação do tempo escolar, como o Programa Escola Integrada, ao objetivar o encontro da escola com o bairro e a cidade no desenvolvimento dos processos educativos, suscita a produção de um espaço geográfico educativo particular fluido e maleável desenhado pela presença de educandos e educadores em circulação no bairro. Dinâmica que auxilia na identificação dos educandos com seu espaço de vivência, motiva novas ações coletivas em prol da melhoria do bairro e potencializa aquelas já existentes. Conquistas, muitas vezes tangenciadas pela prática dos educadores do território, que, em suas ações, têm humanizado a expressão da docência no contexto da Educação Integral.

Recebido em 03 de dezembro de 2015 Aprovado em 15 de agosto de 2016

\section{Notas}

1 No Brasil a ampliação da jornada escolar e a busca por uma formação mais completa é algo culturalmente existente nas classes economicamente privilegiadas, revelado pela grande oferta de educação em tempo integral em instituições de ensino privadas. Neste texto, focalizamos o público que vive em situação de pobreza social e que participam das experiências no âmbito da educação pública.

2 Nome fictício utilizado para fins de pesquisa.

\section{Referências}

ALVES-MAZZOTTI, Alda Judith; GEWANDSZNAJDER, Fernando. O Método nas Ciências Naturais e Sociais: pesquisa quantitativa e qualitativa. São Paulo: Pioneira Thomson, 1999.

AMORIM FILHO, Oswaldo Bueno. Topofilia, Topofobia e Topocídio em Minas Gerais. In: DEL RIO, Vicente; OLIVEIRA, Lívia. Percepção Ambiental: a perspectiva brasileira. São Carlos: UFSCar/Studio Nobel, 1999. P. 139-152.

ARROYO, Miguel Gonzalez. Ofício de Mestre: imagens e auto-imagens. Petrópolis: Vozes, 2000.

ARROYO, Miguel Gonzalez. Currículo, Território em Disputa. Petrópolis: Vozes, 2011.

ARROYO, Miguel Gonzalez. O direito a tempos-espaços de um justo e digno viver. In: MOLL, Jaqueline. Caminhos da Educação Integral no Brasil: direito a outros tempos espaços educativos. Porto Alegre: Penso Editora, 2012a. P. 33-45. ARROYO, Miguel Gonzalez. Outros Sujeitos, Outras Pedagogias. Petrópolis: Vozes, 2012b.

ASSOCIAÇÃO Internacional de Cidades Educadoras. Carta das Cidades Educadoras. 1 ed. Barcelona: 2004. 09 f. Disponível em: <http://www.edcities.org/wp-content/uploads/2013/10/Carta-Portugues.pdf>. Acesso em: 21 jul. 2015.

1224 Educação \& Realidade, Porto Alegre, v. 41, n. 4, p. 1205-1226, out./dez. 2016. 
BRASIL, Ministério da Educação. Caderno Educação Integral. Série Mais Educação. 1 ed. Brasília: 2008. P. 55. Disponível em: <http://portal.mec.gov.br/ dmdocuments/cadfinal_educ_integral.pdf >. Acesso em: 01 out. 2015.

BRASIL, Ministério da Educação. Educação Integral: texto referência para o debate nacional. Série Mais Educação. 1 ed. Brasília: 2009. P. 56. Disponível em: $<$ http://portal.mec.gov.br/dmdocuments/cadfinal_educ_integral.pdf >. Acesso em: 15 nov. 2014.

CARLOS, Ana Fani Alessandri. O lugar no/do Mundo. São Paulo: Hucitec, 1996.

CARVALHO, Paulo Felipe Lopes de. A Escola, o Bairro e a Cidade: processos de formação de territórios educativos na perspectiva da educação integral. 2014. 194 f. Dissertação (Mestrado em Educação) - Programa de Pós-Graduação em Educação, Conhecimento e Inclusão Social, Universidade Federal de Minas Gerais, Belo Horizonte, 2014.

DAYRELL, Juarez Tarcísio; CARVALHO, Levindo Diniz; GEBER, Saulo. Os Jovens Educadores em um Contexto de Educação Integral. In: MOLL, Jaqueline. Caminhos da Educação Integral no Brasil: direito a outros tempos e espaços educativos. Porto Alegre: Penso Editora, 2012. P. 157-171.

DEUS, José Antônio Souza. Geografia Cultural do Brasil/Etnogeografia. Belo Horizonte: Editora UFMG, 2010.

HAESBAERT, Rogério. Território e Multiterritorialidade: um debate. Revista GEOgraphia, Niterói, Universidade Federal Fluminense, v. 9, n. 17, p. 29-46, abr. 2007.

KOZEL, Salete Teixeira, NOGUEIRA, Amélia Regina Batista. Geografia das Representações e sua aplicação pedagógica: contribuições de uma experiência vivida. Revista do Departamento de Geografia, São Paulo, Faculdade de Filosofia e Ciências Humanas da USP, v.13, p. 239-257, jul. 1999.

KOZEL, Salete. Representação do Espaço sob a Ótica dos Conceitos: mundo vivido e dialogismo. In: ENCONTRO NACIONAL DOS GEÓGRAFOS, 1., 2010, Porto Alegre. Anais... Porto Alegre, 2010. P. 11.

MAGNANI, José Guilherme Cantor. De perto e de Dentro: notas para uma etnografia urbana. Revista Brasileira de Ciências Sociais, São Paulo, Associação Nacional de Pós-Graduação e Pesquisa em Ciências Sociais, v. 17, n. 49, p. 11-29, jun. 2002.

MAGNANI, José Guilherme Cantor. Festa no Pedaço: cultura popular e lazer na cidade. São Paulo: Hucitec, 1998.

MAGNANI, José Guilherme Cantor. Território e Multiterritorialidade: um debate. Revista GEOgraphia, Niterói, Universidade Federal Fluminense, ano IX, n. 17, p. 19-45, jan. 2007.

RELPH, Edward. As Bases Fenomenológicas da Geografia. Geografia, Rio Claro, v. 4, n 7, p. 1-25, abr. 1979.

SANTOS, Milton. Território e Sociedade: entrevista com Milton Santos. São Paulo: Fundação Perseu Abramo, 2000.

SANTOS, Milton. A Natureza do Espaço: técnica, tempo, razão e emoção. São Paulo: Edusp, 2009.

SOUZA, Edevaldo Aparecido Souza; PEDON, Nelson Rodrigo. Território e Identidade. Revista da Associação dos Geógrafos Brasileiros, Mato Grosso do Sul, Associação dos Geógrafos Brasileiros. v. 1, n. 6, p. 126-148, nov. 2007.

VILLAR, Maria Belén Caballo. A Cidade Educadora: nova perspectiva de organização e intervenção municipal. Portugal; Lisboa: Instituto Piaget, 2001.

Educação \& Realidade, Porto Alegre, v. 41, n. 4, p. 1205-1226, out./dez. 2016.1225 
Educação (de Tempo) Integral e a Constituição de Territórios Educativos

Lúcia Helena Alvarez Leite é professora Associada da Faculdade de Educação da Universidade Federal de Minas Gerais. Coordenadora do Grupo TEIA (Territórios, Educação Integral e CidadaniA) e pesquisadora nas interfaces entre movimentos sociais e educação, educação integral e educação indígena.

E-mail: lualvarezleite@gmail.com

Paulo Felipe Lopes de Carvalho é mestre e doutorando em Educação pela Faculdade de Educação Universidade Federal de Minas Gerais. Formador de professores em Educação Integral. Professor de Educação Básica/Geografia. E-mail:pfelipegeo@gmail.com 